\title{
Single-Bus and Dual-Bus Architectures of Electrical Power Systems for Small Spacecraft
}

Jesus Gonzalez-Llorente ${ }^{1,2^{\star}}$, Aleksander Andrzej Lidtke, Ronald Hurtado², Kei-lchi Okuyama

\author{
Gonzalez-Lorente J (ID https: / / orcid.org/0000-0001-6525-7657 \\ Lidtke AA (D) https: / / orcid.org/0000-0002-7571-3422 \\ Hurtado R (D) https://orcid.org/0000-0002-3584-6191 \\ Okuyama K (D) https: / / orcid.org/0000-0002-3275-7572
}

\section{How to cite}

Gonzalez-Llorente J; Lidtke AA; Hurtado R; Okuyama K (2019) Single-Bus and Dual-Bus Architectures of Electrical Power Systems for Small Spacecraft. J Aerosp Technol Manag, 11: e4419. https://doi.org/10.5028/jatm.v11.1086

\begin{abstract}
Nowadays, it has become possible for universities and new businesses to launch satellites of reduced size and cost fulfilling viable missions. Nevertheless, there is still a considerable failure rate that reduces the expected lifetime of these spacecraft. One of the main causes of failure is the power system. Redundancy is one of the main options to enhance its lifetime and lower the failure rate. However, cost, mass, and complexity increase due to redundancy, making it more difficult to complete the projects. Thus, it is necessary to enhance the lifetime of power systems while keeping the development process simple and fast. This paper proposes two configurations of an electrical power system with duplicate components: single-bus configuration has been designed for a nanosatellite not yet launched and dual-bus configuration for a micro deep-space probe launched into a heliocentric orbit. The design and implementation of two dual electrical power systems are described; measurements and on-orbit data of the electrical power system of the micro deep-space probe are also presented, demonstrating that the dual-bus electrical power system can be successfully used in spacecraft. Lastly, conclusions regarding the redundancy considerations for small satellite electrical power systems are drawn based on these two examples.
\end{abstract}

KEYWORDS: Small satellites, Solar-powered spacecraft, Redundant components, Power conditioning, Nanosatellites, Redundancy.

\section{INTRODUCTION}

The development of spacecraft by universities has been focused on small satellites, which include nanosatellites, picosatellites and miniaturised deep space probes. Specifically, most university-class missions have adhered to the CubeSat specification to easily obtain a launch opportunity and used Commercial Off-The-Shelf (COTS) components (Carrara et al. 2017) to shorten the development time. The popularity of university-built CubeSats can be demonstrated by reviewing the number of university missions already launched; 266 university-class missions had launched until the end of 2015 (Swartwout and Jayne 2016). Moreover, a new business based on a constellation of CubeSats conducting Earth observation is in operation (Crisp et al. 2015). Similarly, interplanetary and deep-space exploration missions have also been developed by universities (Yoon et al. 2014; Babuscia et al. 2015; Sarli et al. 2015). 
One implicit goal of CubeSat development is having fast and low-cost projects; however, the high probability of failure is a common drawback associated with these projects. The failure rate of university-class missions is about $40 \%$ (Swartwout and Jayne 2016). The electrical power system (EPS) is one of the main causes of failures of CubeSat missions both in early mission phase and during the first three months (Langer and Bouwmeester 2016). Thus, improving the reliability of the EPS will significantly reduce the failure rate of these missions.

In small satellites, simple configurations have predominantly been used for implementing the electrical power systems (Okada et al. 2013; Edries et al. 2016). The power source (PS) of small satellites is typically based on solar cells and lithium batteries as a secondary source (Frost et al. 2015). The electrical power is transferred from the solar cells to the batteries and the spacecraft subsystems using either Maximum Power Point Tracking (MPPT) or Direct Energy Transfer (DET) architectures (Patel 2005; Mourra et al. 2010). In any case, a battery charge regulator (BCR) is required to protect the battery against overvoltage or overcurrent, and power conditioning modules (PCM) are needed to regulate and distribute the voltage for satellite subsystems. Figure 1a shows the architecture of a simple EPS, showing its interfaces with main subsystems of the spacecraft: On-board Computer (OBC), Communication System (COM), Attitude Determination and Control System (ADCS), and Payload (PL). Figure 1b shows the block diagram of main components of a PCM.

(a)

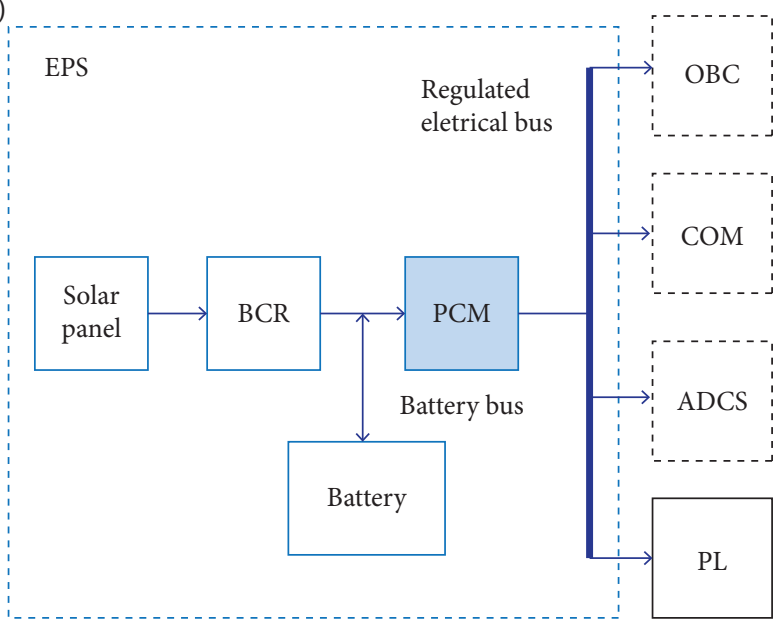

(b)

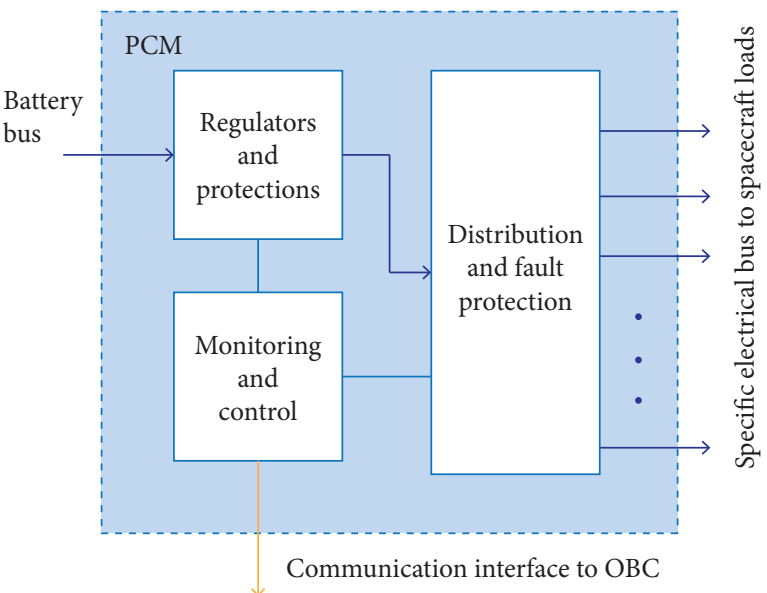

Figure 1. (a) Architecture of simple electrical power system on a small spacecraft and its interfaces with other subsystems. (b) Block diagram of a PCM indicating functional components.

Placing two identical components in parallel significantly increases the reliability of a system, reduces the operating stress on the components and prolongs their expected life (Patel 2005). Splitting the power conditioning unit has been studied in high-power spacecraft to ease thermal control and to double the output power capacity (Loche et al. 2011). In this paper, two configurations with dual electrical power systems are presented. These configurations have been developed for a nanosatellite and a micro deep-space probe, Shinen-2 (Kuroiwa et al. 2016), launched in December 2014 on-board H-IIA-202. The next section of this paper presents the general approach to the implementation of the dual-bus electrical power systems for two cases. Then, a detailed comparison of the two case studies for a nanosatellite and deep-space probe is made. Because the two missions have different needs, this comparison is focused on showing the performance of different units used in the implementation of the EPS, not the overall systems. The objective is to provide reference designs of the EPS functional units for future spacecraft. The results section shows measurements of the performance of the two case studies including on-orbit data from the deep-space probe, and the theoretical failure rate is discussed. Finally, conclusions regarding the merits of a dual-bus EPS architecture in the context of small satellites are drawn. 


\section{APPROACH OF DUAL-BUS ELECTRICAL POWER SYSTEM ARCHITECTURE}

Most spacecraft are designed to achieve specific missions performing different functions in science, technology demonstration or education. For university-class spacecraft, receiving the housekeeping data of the satellite is usually considered minimum success of the mission because one of the primary objectives is education. It is thus considered sufficient for the team, formed mainly of students, to be able to develop a functional spacecraft. In cases with multiple mission objectives, it is usual to consider multiple reliability requirements; achieving any of these requirements is a level of the mission success (Hecht 2011). For example, in the hypothetical case of one spacecraft with two missions and two payloads (PL-1 and PL-2), the mission requirements could include the following:

- At least PL-1 shall be operational for minimum success of mission 1;

- At least PL-2 shall be operational for minimum success of mission 2;

- $\quad$ Both PL-1 and PL-2 shall be operational for full mission success.

Usually, including more components needed to satisfy the minimum success is a common way to increasing the reliability of the mission. However, more components usually increase the cost and development time. As figure of merit (FOM), probability of failure (given by 1 - reliability) and cost of units in parallel can be used as trade-off criteria when designing an architecture with redundancy. The theoretical relationship between these two FOMs - that does not account for e.g. cost reduction with mass production - is shown in Fig. 2. It can be seen that the highest increase in reliability (or the highest decrease of probability of failure) is achieved with two components in parallel and the cost is increased linearly with the number of units (Patel 2005). Thus, two EPS designs approach are presented below: single-bus electrical with two units and two units in a dual-bus; adding subsequent buses would follow the law of diminishing returns but would be associated with substantial increases in cost and complexity.

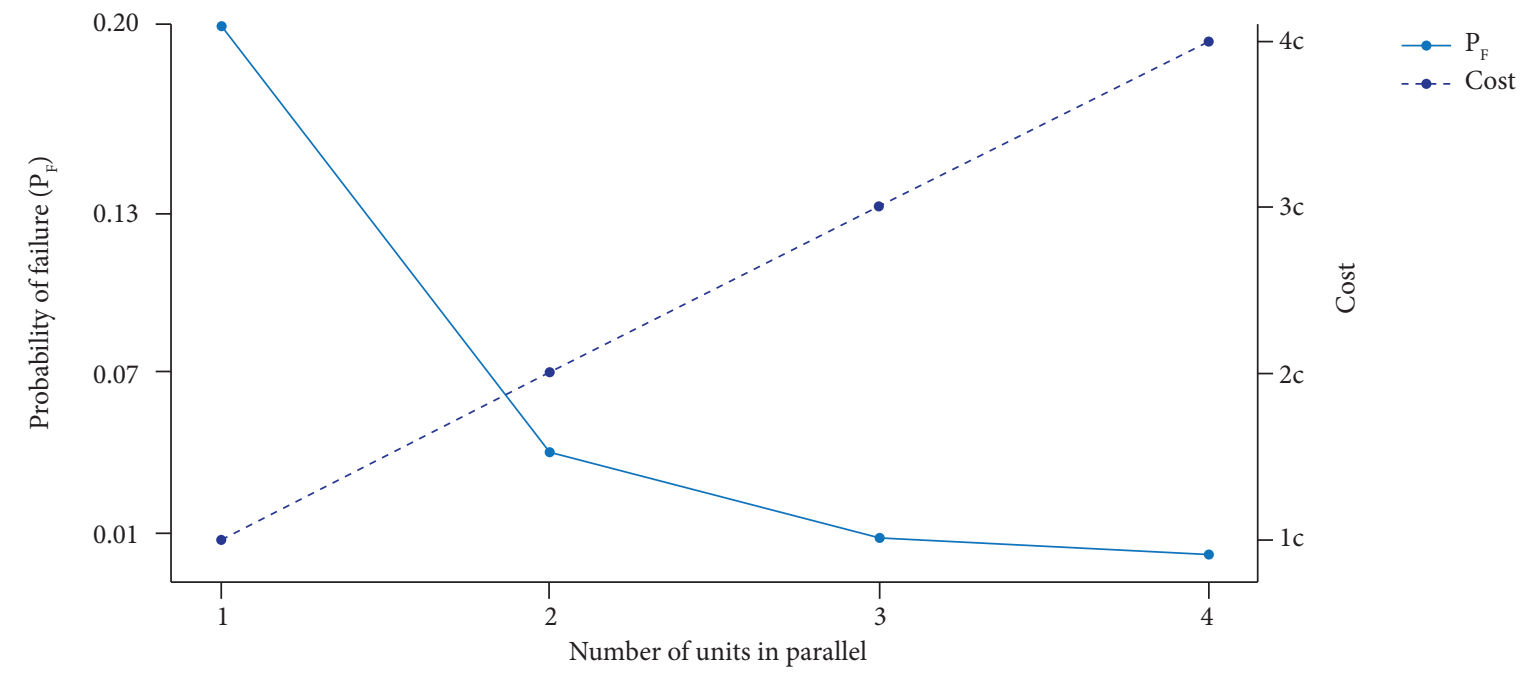

Figure 2. Probability of failure and cost versus the number of units in parallel. Decrease of probability of failure for units placed in parallel is minimum for more than three units; however cost is increasing significantly.

\section{SINGLE-BUS ELECTRICAL POWER SYSTEM}

A generalized architecture of the considered single bus EPS is shown in Fig. 3. The architecture is split into two systems, EPS 1 and EPS 2. Each EPS consists of a power source (PS), battery, BCR and PCM. In a simple case, both systems have the same power capability and can provide the power required for all operation modes of the spacecraft. However, this case might be unattractive due to the mass and dimensional penalties implied by duplicating every component. 
One variation of the redundant architecture is to size the power sources of EPS 2 for operation of only the essential elements needed to achieve the minimum success of the mission (Fig. 3b). For example, only OBC, COM and payload 2 (PL-2) may need to be powered from this bus; it means that ADCS is only an essential element for mission of payload (PL-1).

(a)

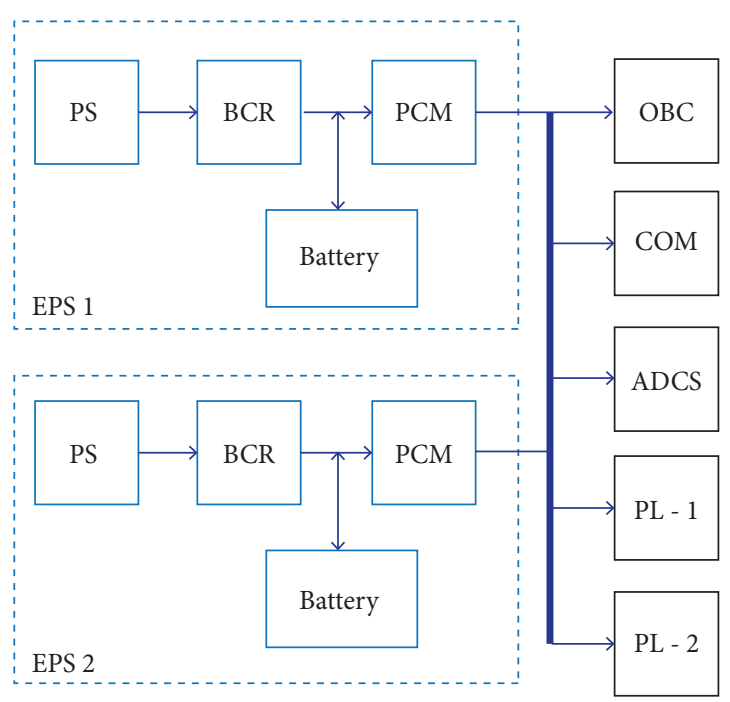

(b)

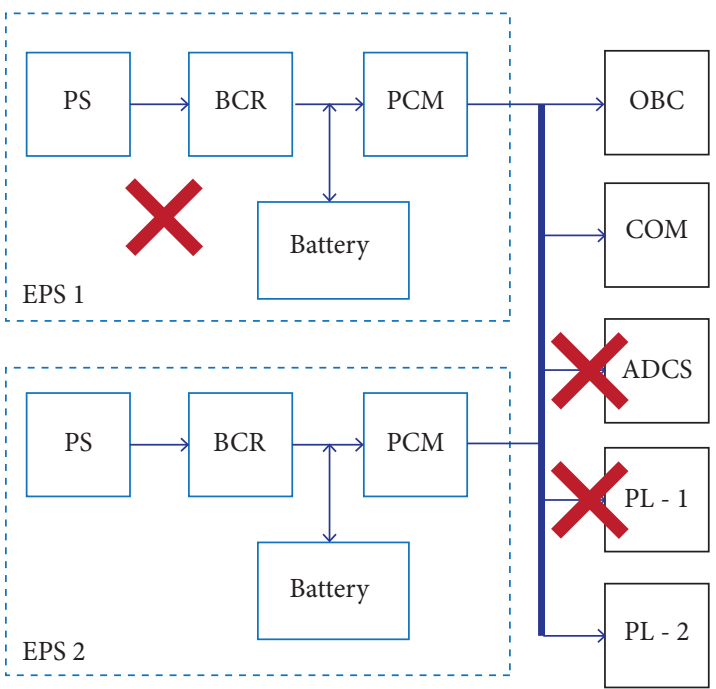

Figure 3. (a) Architecture of single bus electrical power system with duplicated EPS. (b) A failure in EPS 1 will prevent the operation of PL-1 and ADCS indicated by the red marks. EPS 2 can be designed to support essential elements for minimum satellite success, i.e. OBC, COM and PL-2.

In the case where EPS 2 only needs to provide power for selected subsystems, the number of solar cells and battery capacity are calculated according to the power profile of these subsystems. The capacity of battery- 2 in Wh $\left(E_{\text {Battery } 2}\right)$ is calculated by $(E q .1)$

$$
E_{\text {Battery } 2}=\frac{P_{O B C} \cdot T_{O B C}+P_{C O M} \cdot T_{C O M}+P_{P L 1} \cdot T_{P L 1}}{D O D_{B a t t e r y 2} \cdot \eta_{2}}
$$

where: $P_{O B C}, P_{C O M}, P_{P L 1}, T_{O B C}, T_{C O M}, T_{P L 1}$ are the power and time required for OBC, COM and PL1 during eclipse; $D O D_{B a t t e r y 2}$ is the depth of discharge for battery-2; and $\eta_{2}$ is the efficiency of the charge/discharge modules.

\section{DUAL-BUS ELECTRICAL POWER SYSTEM}

The spacecraft can include redundancy of subsystems different to the EPS such as OBC and COM to increase the probability of mission success. These additional subsystems are not necessarily identical to avoid the same errors when executing the same operation, e.g. two communication subsystems might use different frequency bands (Del Corso et al. 2011). The dual-bus architecture for this case can be implemented as shown in Fig. 4. Here, the two power buses are separated. Thus, EPS 2 provides power just to the communication (COM-2), the controller unit (OBC-2) and the secondary payload (PL-2).

The main reason to include dual electrical power systems is to reduce the failure rate of the whole spacecraft. Thus, the spacecraft should be able to operate when one of the power systems fails. This is the case for the micro deep-space probe Shinen-2, where the dual-bus is implemented: one bus provides power to the sensing payload (radiation particle detector) and one communication subsystem, while the other bus provides power to another communication subsystem that is sufficient for up-and down-link on its own. Different approach is implemented in the nanosatellite. It is not made fully redundant because the secondary power system 
can only provide power for minimum operating conditions. Namely, OBC and COM have backup power lines from a separate power source. These two power systems will be analyzed in next section.

(a)

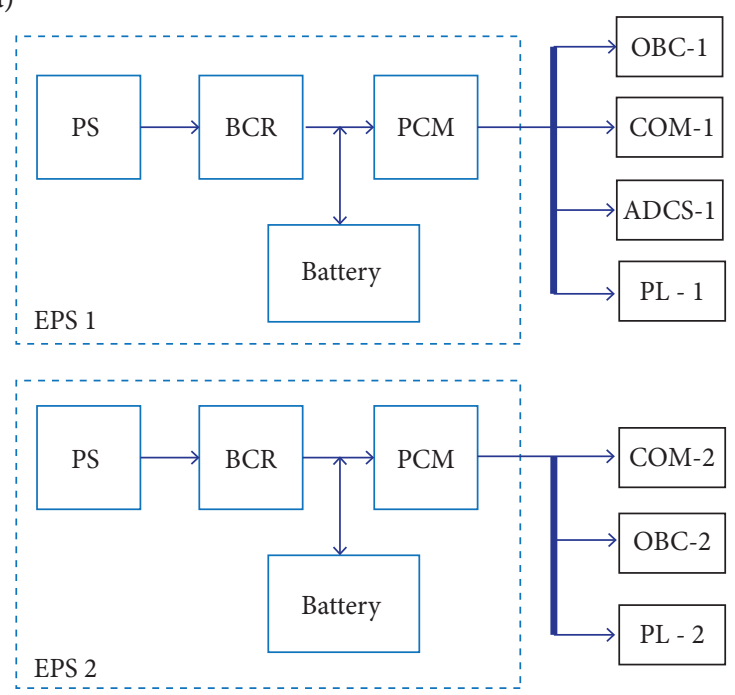

(b)

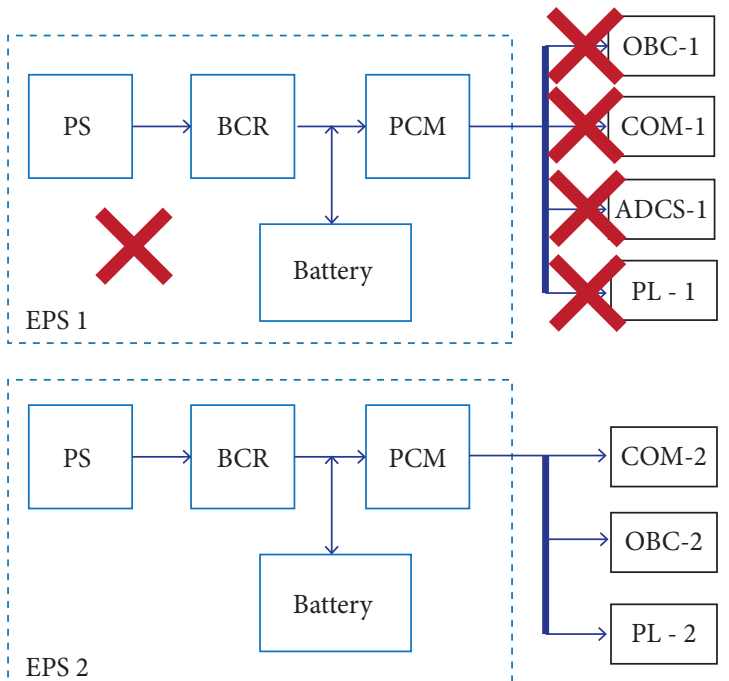

Figure 4. (a) Architecture of dual-bus electrical power system with duplicate components. (b) A failure, indicated by the red marks, in EPS 1 will cause the loss of OBC-1, COM-1, ADCS-1 and PL-1. However, COM-2, OBC-2 and PL-2 can still operate receiving the power from EPS 2 .

\section{COMPARISON OF TWO CASES OF DUAL-BUS ELECTRICAL POWER SYSTEM SPACECRAFT DESCRIPTION}

The nanosatellite taken as example here is a three-unit (3U) CubeSat with dimensions $30 \times 10 \times 10 \mathrm{~cm}$ and mass of $4 \mathrm{~kg}$ (Fig. 5a). The main mission is to take a photograph of the Earth using a camera developed with COTS components. Moreover, this is a university-class mission that involves students in the development team as part of education and research projects.

(a)

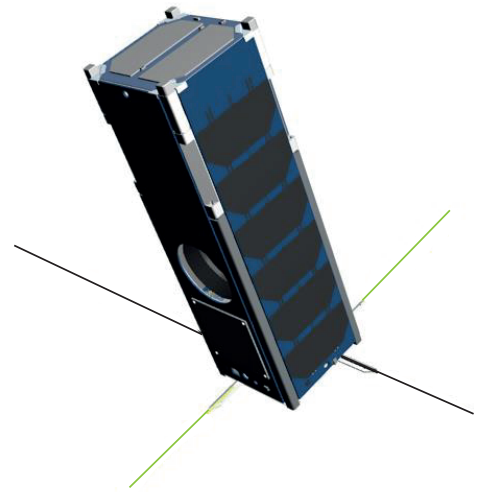

(b)

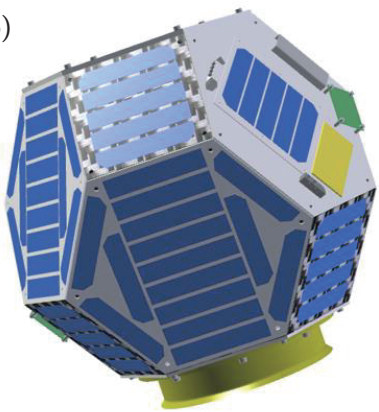

Figure 5. Example of two small spacecraft with body mounted solar arrays: (a) Nanosatelite following the three unit CubeSat dimensions; (b) Micro deep-space probe Shinen-2.

The exemplar micro deep-space probe Shinen-2, has a quasi-spherical shape, diameter of about $50 \mathrm{~cm}$ and mass of $18 \mathrm{~kg}$ (Fig. 5b). This probe was developed with three purposes: firstly, to demonstrate a structure based on Carbon Fiber Reinforced 
Thermoplastic (CFRTP); secondly, to measure radiation from Earth to deep space with a charge particle detector, and thirdly, to demonstrate a deep space communication method (Bendoukha et al. 2016).

\section{COMPARISON OF ARCHITECTURES}

The electrical power system of Shinen-2 uses a dual-bus system with duplicate components, as described in the previous section. A block diagram of the dual electrical power system of Shinen-2 is shown in Fig. 6 . This redundant system aims to have an independent power line for each communication line. Thus, EPS 1 provides power to the main communication line (COM-1) that includes the beacon transmitter (TX-Beacon), the OBC-1 and the main payload (PL-1). The EPS 2 provides power to the deep-space communication (COM-2) that is itself a technology demonstration payload (PL-2). Both power systems include Solar Array Panels (SAPs) as power source (PS), Maximum Power Point Tracking (MPPT) as BCR, Power Conditioning Module (PCM) and protections.

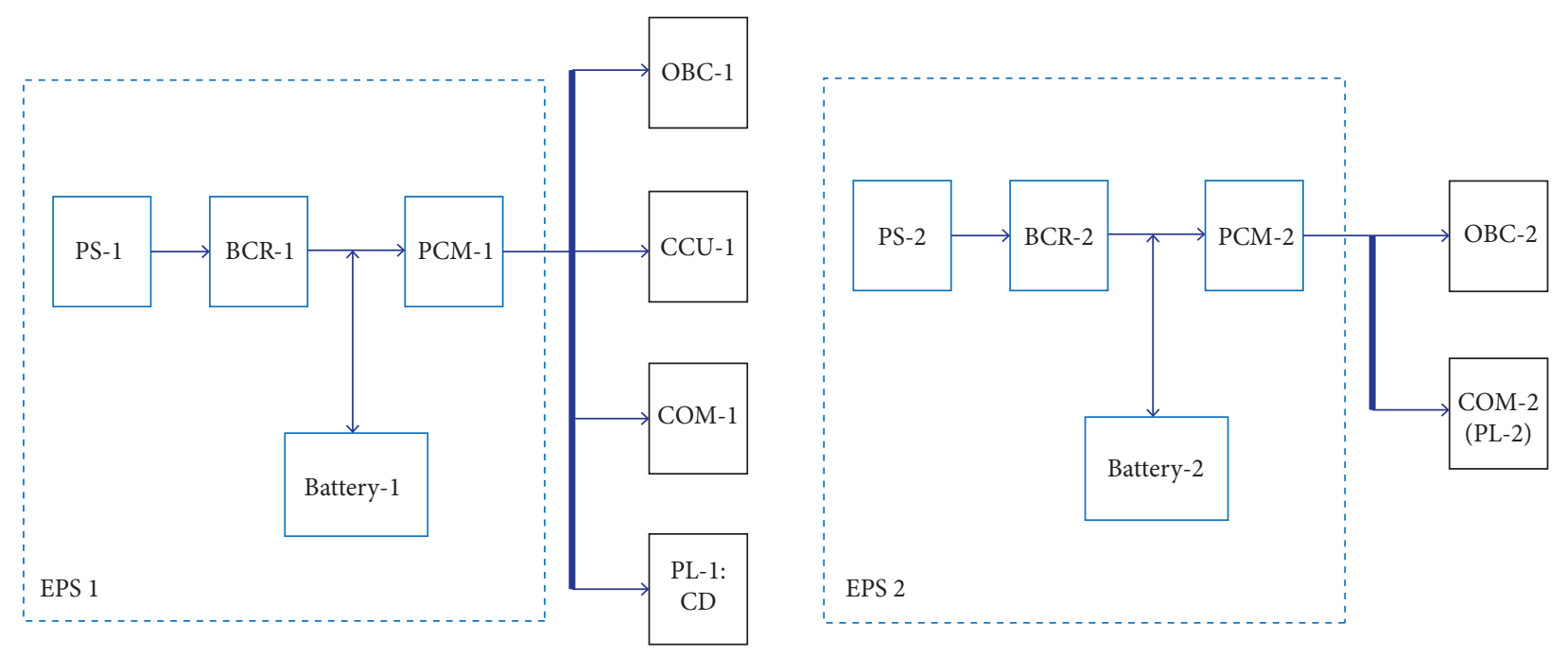

Figure 6. Electrical power system architecture of micro deep-space probe Shinen-2.

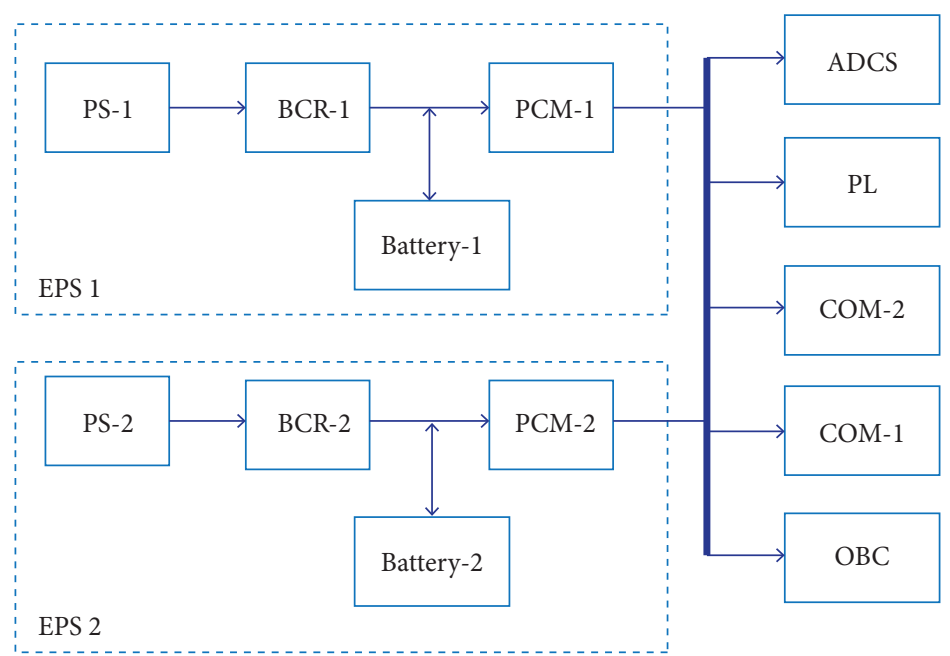

Figure 7. Power distribution of nanosatellite. EPS 2 has enough installed capacity to power only the OBC and COM-2 subsystems, while EPS 1 can power all subsystems. Hot redundancy is used selecting DC-DC converters that support parallel connection. 
Instead of using the dual-bus power system, the electrical power system of the nanosatellite uses a single-bus electrical power system. However, the components of EPS 2 are sized for minimum operation condition (OBC and COM-1), as described in previous section, and EPS 1 is sized for full operation (OBC, COM-1, COM-2, ADCS and PL). EPS 2 is called secondary power system and provides less power than the solar arrays used in the EPS 1 (main power system). The operating modes relying on the secondary power system are designed to use only the essential subsystems and have a positive power budget. A block diagram of the EPS of the nanosatellite is shown in Fig. 7. The description of each component is presented in the following section. Implementation of hot redundancy can be used by careful selection of DC-DC converters that achieve stable voltage regulation and load sharing when operated in a parallel connection (Mishra 2019).

\section{SOLAR ARRAY CONFIGURATION}

The nanosatellite is a $3 \mathrm{U}$ CubeSat with six sides on which the solar panels are body-mounted, as shown in Fig. 5a. In this case, the panels on the $3 \mathrm{U}$ faces of the satellite are the power source for the primary power system (EPS 1 ), while the solar panels on the $1 \mathrm{U}$ faces are connected to the secondary power system (EPS 2). As described before, the secondary power system has less installed power, which is sufficient only for minimum operation of the satellite. The micro deep-space probe has 13 sides with solar arrays, 7 sides for EPS and 6 sides for EPS 2. Thus, both power systems have almost the same amount of installed power.

In the nanosatellite, the solar panels are composed of multijunction solar cells with efficiency of $30 \%$, an open circuit voltage of 2.7 V, and a short circuit current of 0.520 A (Azur Space 2016). Each solar panel of the primary system consists of 6 solar cells connected in series to obtain a voltage of $16.2 \mathrm{~V}$ with a short circuit current of $0.520 \mathrm{~A}$ and maximum power of 7.2 W. The two solar panels of the secondary system are composed of 2 solar cells in series. Therefore, their open circuit voltage is $5.4 \mathrm{~V}$, the short circuit current is $0.520 \mathrm{~A}$ and maximum power is $2.4 \mathrm{~W}$.

Different to the nanosatellite, the solar array in the micro deep-space probe Shinen-2 uses Silicon solar cells with efficiency of $17 \%$, open circuit voltage of $0.632 \mathrm{~V}$ and short circuit current of $1.12 \mathrm{~A}$. The solar array consists of five such solar cells connected in series and generates at most $2.78 \mathrm{~W}$. In Shinen-2, 11 solar arrays are installed on seven sides as power source of EPS 1 (30.58 W), while the EPS 2 consists of 10 arrays $(27.8 \mathrm{~W})$ distributed on six sides.

In brief, the nanosatellite has one kind of array of solar cells for each subsystem, i.e., the solar arrays are in a dual-bus configuration because they are not connected. The installed power in the primary EPS is $21.6 \mathrm{~W}$ raised using three solar arrays, and the secondary EPS has installed power of $4.8 \mathrm{~W}$ with two arrays. The micro deep-space probe has only one kind of array that is used for the two subsystems. The summary of solar arrays configuration of both spacecraft is shown in Table 1 .

Table 1. Specification of solar array configuration for each EPS of the nanosatellite and micro deep-space probe.

\begin{tabular}{|c|c|c|c|c|c|}
\hline \multirow{2}{*}{ Spacecraft } & \multirow{3}{*}{ Subsystem } & \multicolumn{4}{|c|}{ Solar array features } \\
\cline { 3 - 7 } & & Isc (A) & Voc [V] & Pm (W) & Number of arrays \\
\hline \multirow{2}{*}{ Nanosatellite } & Primary & 0.52 & 16.2 & 7.2 & 3 \\
\hline \multirow{2}{*}{ Micro deep-space probe } & Secondary & 0.52 & 5.4 & 2.4 & 2 \\
& Bus-1 & 1.12 & 3.16 & 2.78 & 11 \\
& Bus-2 & 1.12 & 3.16 & 2.78 & 10 \\
\hline
\end{tabular}

\section{BATTERY CONFIGURATION}

The same battery cell, lithium-ion, is used in both spacecraft because this kind of cells has become the preferred choice for most of the small satellites. Thus there is enough space heritage to rely on this energy storage technology (Chin et al. 2018; Navarathinam et al. 2011). These cells have the following characteristics: nominal voltage of $3.7 \mathrm{~V}$ with a capacity of $3200 \mathrm{mAh}$ (Sanyo Energy 2012). Even though both spacecraft use the same battery cells, the battery array is different for each spacecraft and for each subsystem. The battery array configuration is summarized in Table 2. 
Table 2. Specification of battery configuration for each EPS of the nanosatellite and micro deep-space probe.

\begin{tabular}{|c|c|c|c|c|}
\hline \multirow{2}{*}{ Spacecraft } & \multirow{2}{*}{ Subsystem } & \multicolumn{3}{|c|}{ Battery array features } \\
\cline { 2 - 5 } & Primary & No series & No. Parallel & No. cells \\
\hline \multirow{2}{*}{ Nanosatellite } & Secondary & 2 & 2 & 4 \\
\hline \multirow{2}{*}{ Small probe } & Bus-1 & 1 & 2 & 16 \\
\hline
\end{tabular}

\section{POWER REGULATOR}

The nanosatellite uses MPPT in the main power system to obtain the maximum power from the solar panels by using the integrated circuit LT3652, which implements a Constant voltage (CV) MPPT technique (Brito et al. 2013). In addition, the LT3652 is a battery management chip that regulates and protects the batteries during charging. The panels on opposite faces of the satellite are connected to the same MPPT because they do not receive solar radiation at the same time. The secondary system does not use MPPT technique because the solar panels in the secondary system have a maximum voltage of $5 \mathrm{~V}$ and the DET connection is the most appropriate for low-voltage solar panels (Erb et al. 2011).

The micro deep-space probe uses MPPT for each solar array. This arrangement is more effective in this case because the solar arrays will receive solar radiation at different angles. Thus they will have different maximum power points. The SPV1040 IC was used to track maximum power. This IC also detects the voltage of the battery to protect it during charging. Table 3 summarizes the characteristics of two ICs.

Table 3. Summary characteristics of the MPPT integrated circuits used in the nanosatellite and the micro deep-space probe.

\begin{tabular}{|c|c|c|}
\hline & SPV1040 & LT3652 \\
\hline Topology & Boost & Buck \\
\hline MPPT & Perturb and observe & Constant voltage \\
\hline Input voltage $(\mathrm{V})$ & 0.3 to 5.3 & 4.9 to 32.0 \\
\hline Maximum current $(\mathrm{A})$ & 1.8 & 2.0 \\
\hline Temperature range $\left({ }^{\circ} \mathrm{C}\right)$ & -40 to 125 & -40 to 125 \\
\hline
\end{tabular}

\section{POWER CONDITIONING AND DISTRIBUTION UNIT}

In the nanosatellite, the primary PCMs consist of two buck DC-DC converters to generate 5 and $3.3 \mathrm{~V}$ (the used IC was TPS62143). These converters have a maximum efficiency of $90 \%$ and an input voltage range from 3 to $17 \mathrm{~V}$. The buck topology was selected because the input voltage in the converters is always above of the output voltage. The input voltage is $13.48 \mathrm{~V}$ if the solar panels are illuminated and $7.2 \mathrm{~V}$ (the battery voltage) in eclipse.

The secondary PCMs are composed of two buck-boost DC-DC converters to generate the same voltages of 5 and $3.3 \mathrm{~V}$ as the primary PCMs. The buck-boost topology was selected because the input voltage range for the converters is from 3.2 to $4.2 \mathrm{~V}$, corresponding to the secondary battery voltage.

In the case of Shinen-2, the two PCUs use the same kind of PCM. The main PCM consists of boost converters to generate $5.0 \mathrm{~V}$ from the battery bus, which can vary from 2.8 to $4.2 \mathrm{~V}$. This conversion is implemented using the LT1370 IC, which is a high frequency switching regulator with minimum voltage of $2.7 \mathrm{~V}$ and maximum current of $6 \mathrm{~A}$. In addition, the LT1316 is used to provide $5.0 \mathrm{~V}$ to digital circuits. This is a boost-type switching regulator that provides maximum current of $0.5 \mathrm{~A}$. 


\section{RESULTS AND DISCUSSIONS \\ RESULTS OF IMPLEMENTATION AND MEASUREMENTS}

The array of six triple junction solar cells, used in the nanosatellite case, is shown in Fig. 8a. The percentage of the area covered by the solar cells is $60 \%$. The hexagonal solar panel of Shinen-2 is shown in Fig. $8 \mathrm{~b}$. This solar panel consists of three primary arrays of five silicon solar cells each. The percentage of the array area covered by solar cells is $70 \%$.

(a)

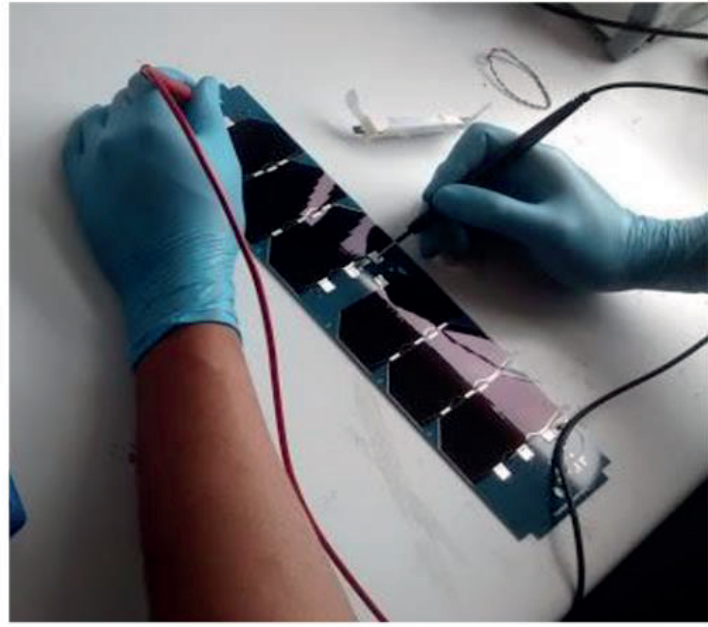

(b)

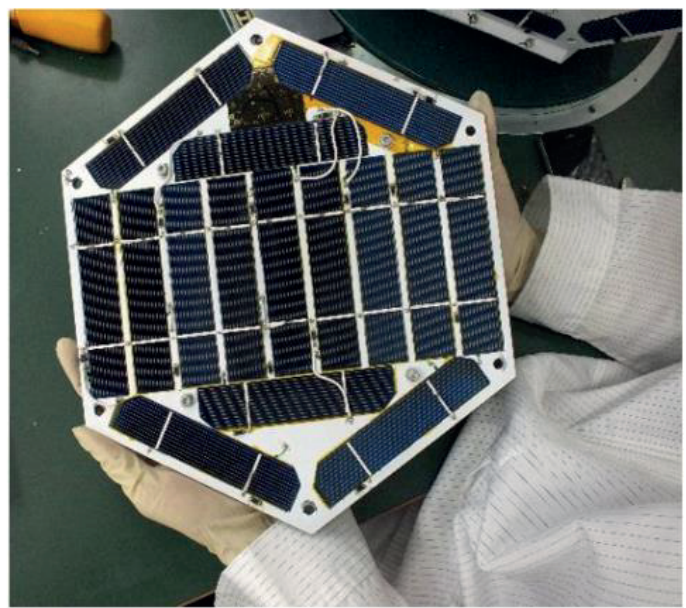

Figure 8. (a) Solar panel of the nanosatellite; (b) Solar panel of the micro deep-space probe.

The board of the electrical power system of nanosatellite is shown in Fig. 9. Both primary and secondary systems are included in the same PCB, and a PC/104-compatible connector is used as the only interface. In this case with redundancy in the same $\mathrm{PCB}$, proper routing and isolation methodology is followed to avoid failure propagation between the circuits. A functional test was completed to verify the operation of the power conditioning unit and measure the converters' efficiency in obtaining $5.0 \mathrm{~V}$ and 3.3 V. The results of these efficiency tests are shown in Fig. 10, respectively. The maximum efficiency was $93.87 \%$ for the $5.0 \mathrm{~V}$ regulator (TPS62143) and 87.4\% for the $3.3 \mathrm{~V}$ regulator (TPS62142). These efficiencies were consistent with the efficiencies of around $90 \%$ specified by the manufacturer.

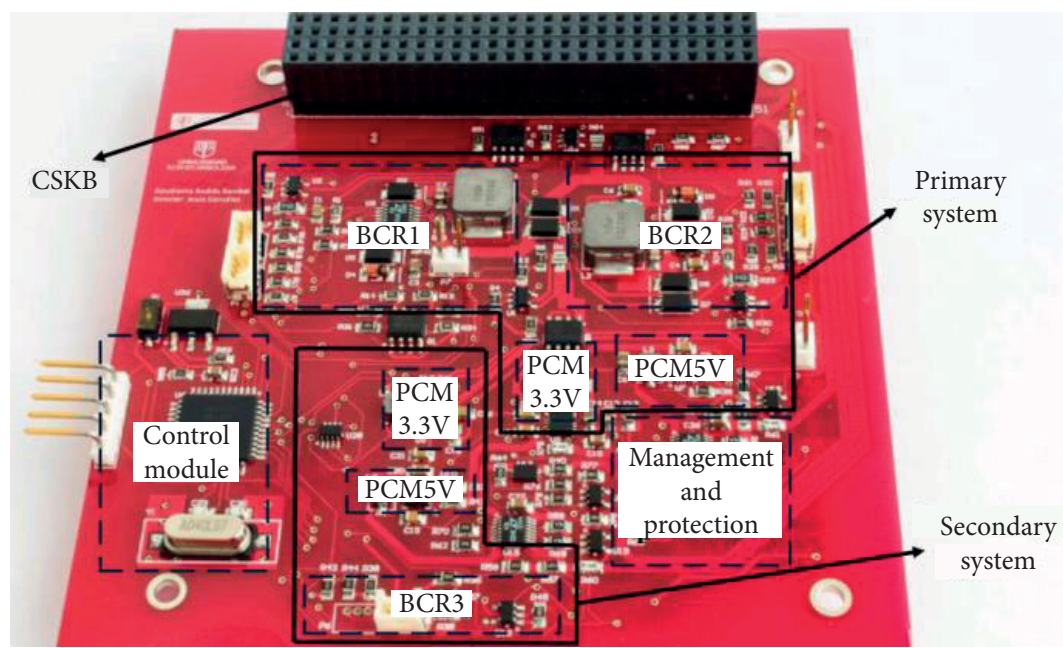

Figure 9. PCB including the two electrical power systems of the nanosatellite. 


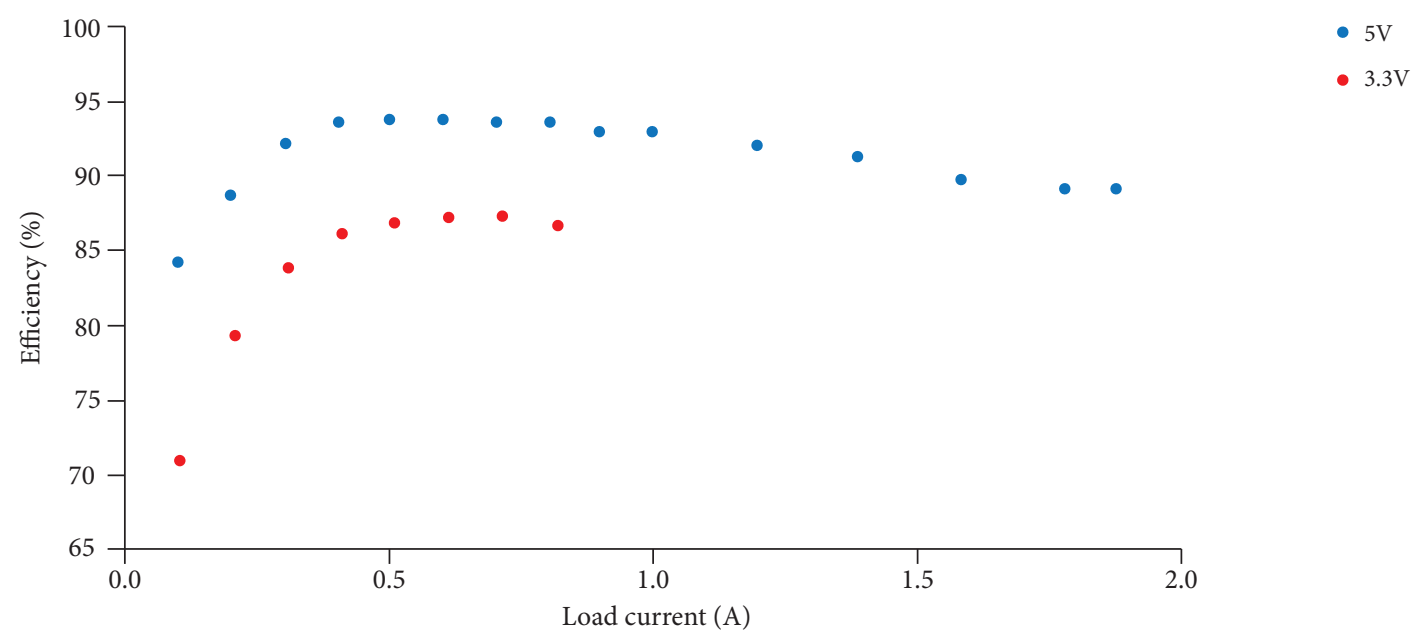

Figure 10. Converter efficiency with input voltage of $7.2 \mathrm{~V}$ for output voltage of $5 \mathrm{~V}$ (TPS62143) and output voltage of $3.3 \mathrm{~V}$ (TPS62142).

The printed circuit board of the power conditioning unit of the Shinen2 is shown in Fig. 11. In addition to the power conditioning modules, this board includes a microcontroller, and voltage and current sensors used to acquire housekeeping data. The results of efficiency tests of the DC-DC converter (LT1370) when it operates at battery voltage of $3.7 \mathrm{~V}$ to generate the regulated but at 5V are shown in Fig. 12.

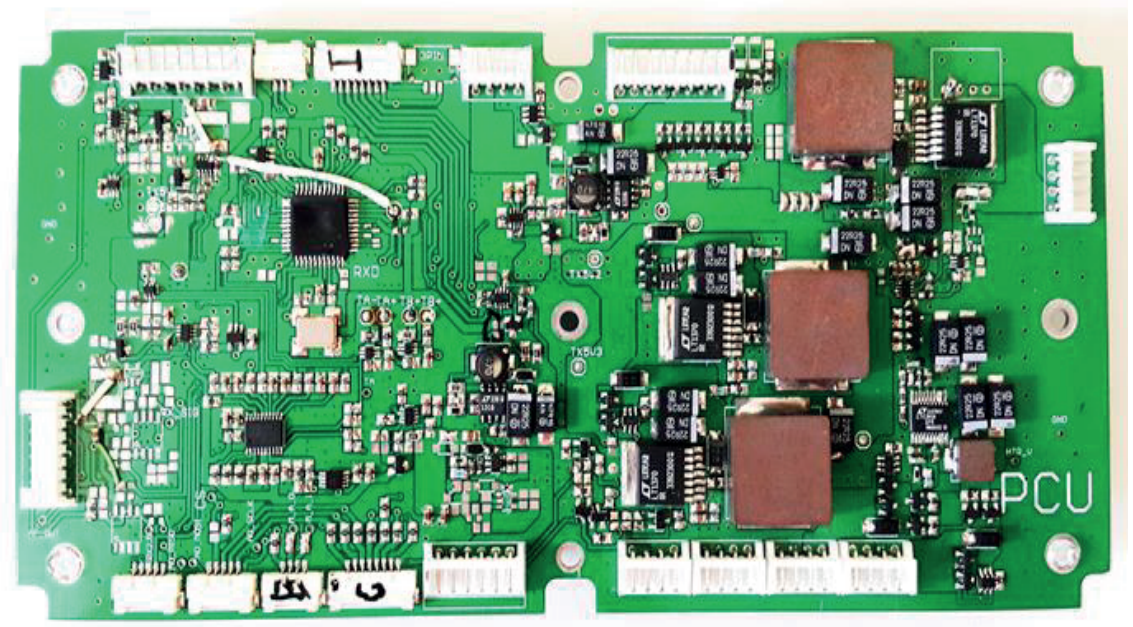

Figure 11. EPS board with the power conditioning unit of the micro-deep space probe.

Even though Shinen-2 was able to communicate until it reached the distance of 2.3 million $\mathrm{km}$ from Earth, the telemetry data about power systems was only analyzed until $700.000 \mathrm{~km}$ because beyond this range the signal was weak and difficult to decode. This is about twice the distance from Earth to the Moon (Kuroiwa et al. 2016). Even within this distance, it was difficult to reliably decode all transmitted telemetry, which renders the usable data scarce.

The histories of the Shinen-2 EPS 1 battery voltage are shown in Fig. 13. The data are plotted against the distance between Shinen-2 and the Earth. The operating voltage varied between 3.88 and $4.06 \mathrm{~V}$, which is similar to the battery of EPS 2. Figure 14 shows the solar array current telemetry; the solar array EPS 1 was located on square face where only one array could be installed, 


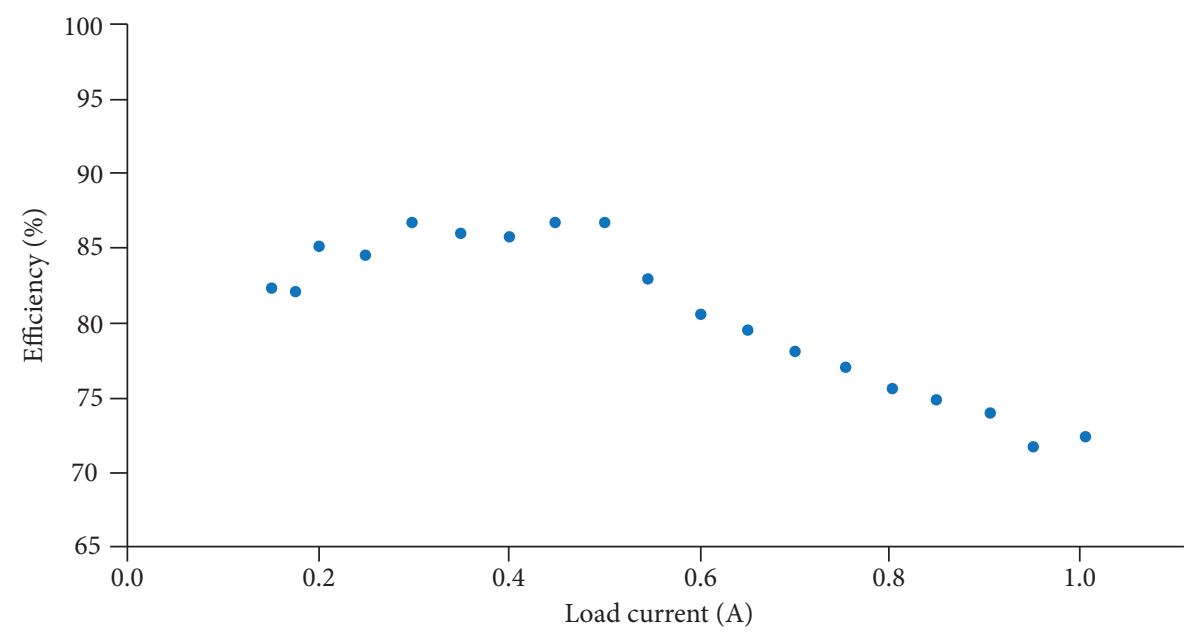

Figure 12. Converter efficiency with input voltage of $3.7 \mathrm{~V}$ for output voltage of $5 \mathrm{~V}$ (LT1370).

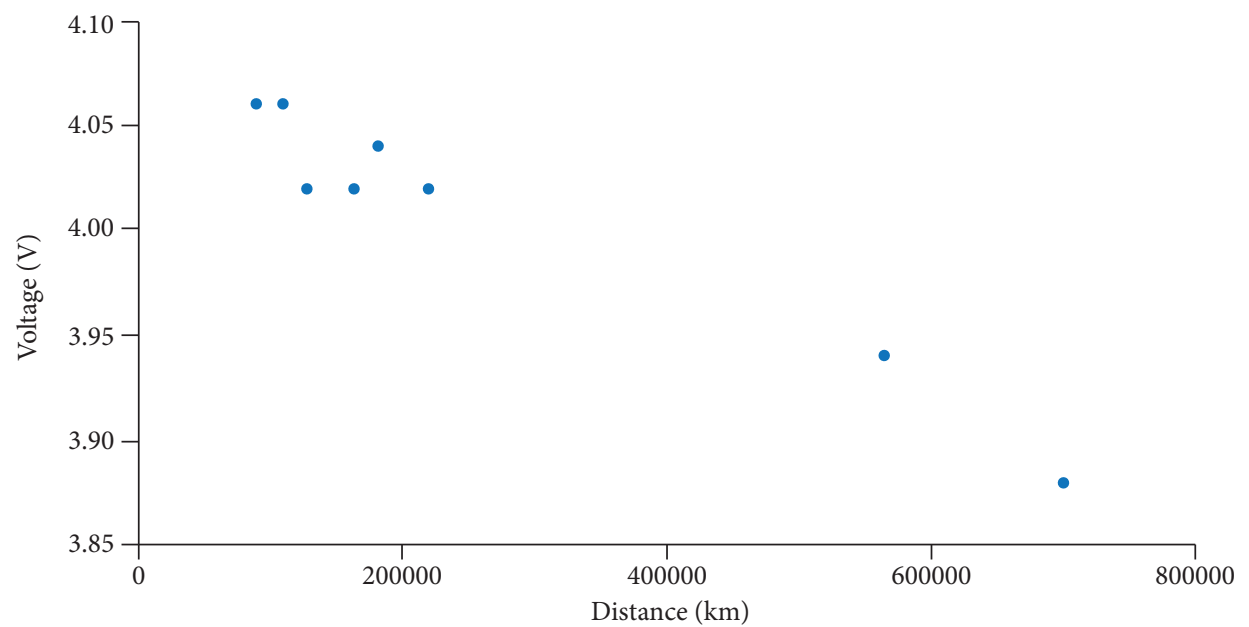

Figure 13. Battery voltage of EPS-1 of Shinen-2 micro deep-space probe, obtained from the spacecraft telemetry.

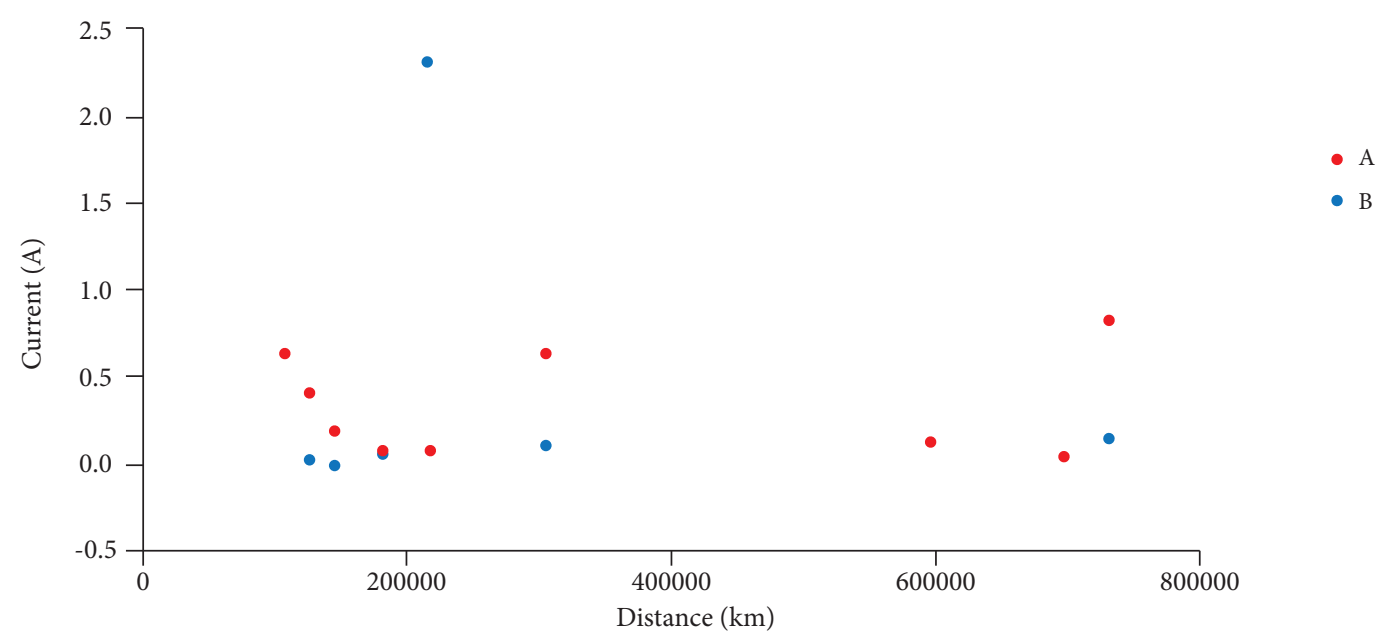

Figure 14. Solar array current of one array on square face (A) and three arrays on hexagonal face (B) of Shinen-2 micro deep-space probe, obtained from spacecraft telemetry. 
and solar array of EPS 2 was located on hexagonal face where three arrays were installed (Fig. $8 \mathrm{~b}$ ). It can be observed that $0.8 \mathrm{~A}$ and 2.4 A were obtained for EPS 1 and EPS 2, respectively; these values are close to the current at maximum power (1.0 A).

\section{DISCUSSION OF FAILURE RATE}

The nanosatellite and the deep-space probe use single- and dual-bus power systems, respectively. These are variations of the simplest possible architecture of an electrical power system with no redundancy. This section presents an analysis of these architectures focused on the failure probability.

Given components A and B, e.g. overcurrent protection and regulation ICs, each with a failure probability $P_{A}$ and $P_{B}$. Different arrangements of these components will result in different failure probabilities of the complete A-B assembly, $P_{F}$. Note that the analysis presented here applies directly to the EPS architectures presented before, even though the actual equations may need to be written for more than only two components. Limiting the analysis to only two components makes the results more succinct. It is therefore favored over an in-depth failure probability analysis of the presented exemplar EPS architectures.

Different ways in which components A and B can be arranged are schematically shown in Fig. 15. For the sake of clarity, only dual redundancy is shown, even though more than two components could be placed in parallel to further reduce $P_{F}$. Also note that $P_{F}$ analyzed here is the probability of failure, i.e. the complement of reliability.

For the simplest, single string arrangement from Fig. 15c, the failure probability is the highest of the three presented in Fig. 15 (DeGroot and Schervish 2014) (Eq. 2):

$$
P_{F, c}=P(A \cup B)=P_{A}+P_{B}-P_{A} P_{B}
$$

However, such a system is the least complicated and thus the quickest to test and implement. Moreover, it requires the least PCB space, which might be an important design consideration for satellites with high volume constraints such as CubeSats. Thus, such a design might be favored in schedule-constrained projects with limited resources, e.g. educational nanosatellite projects. The failure probability of the fully-redundant (cross-strapped) system shown in Fig. 15b is given as the failure of both A components or both B components (Eq. 3):

$$
P_{F, b}=P\left(A_{1} \cap A_{2}\right) \cup P\left(B_{1} \cap B_{2}\right)=P_{A_{1}} P_{A_{2}}+P_{B_{1}} P_{B_{2}}-P_{A_{1}} P_{A_{2}} P_{B_{1}} P_{B_{2}}
$$

The dual redundant power system shown in Fig. 15a offers a middle ground between the fully redundant and single-string systems. Its failure probability is given as (Eq. 4):

$$
\begin{aligned}
P_{F, a} & =\left(P_{A_{1}} \cup P_{B_{1}}\right) \cap\left(P_{A_{2}} \cup P_{B_{2}}\right)=\left(P_{A_{1}}+P_{B_{1}}\right)\left(P_{A_{2}}+P_{B_{2}}\right)= \\
& =P_{A_{1}} P_{A_{2}}+P_{A_{1}} P_{B_{2}}+P_{B_{1}} P_{A_{2}}+P_{B_{1}} P_{B_{2}}-P_{A_{1}} P_{A_{2}} P_{B_{2}}-P_{B_{1}} P_{B_{2}} P_{A_{2}}-P_{A_{1}} P_{A_{2}} P_{B_{1}}- \\
& -P_{B_{1}} P_{B_{2}} P_{A_{1}}+P_{A_{1}} P_{A_{2}} P_{B_{1}} P_{B_{2}} .
\end{aligned}
$$

By noting that $P_{A, 1}, P_{A, 2}, P_{B, 1}$ and $P_{B, 2}$ are always less than or equal to 1.0, one can observe that $P_{F, b}<P_{F, a}<P_{F, c}$, i.e. that the fully cross-strapped system has the lowest failure probability of all three. However, this assumes that the connections between components A and B have the same failure probability as in the case of single-string system. This might not be the case if the 
connections are realized with harness, and are manufactured and tested by inexperienced students, for example (Shirasaka et al. 2010). Depending on the complexity of the circuits that components A and B require, the complexity of the complete A-B system in the fully cross-strapped configuration might reach a level where design flaws will be difficult to identify in a timely fashion, thus leading to an on-orbit failure or missing the launch window.

Even though $P_{F a}$ is theoretically higher than the failure probability of the fully redundant system, $P_{F, b}$, the reduced system complexity might result in lower $P_{F}$ in practice due to design errors and insufficient testing (Shirasaka et al. 2010). Still, $P_{F, a}$ of the dual bus system is less than the $P_{F, c}$ of the single string system. Moreover, if the secondary power system is scaled to only provide the power necessary to satisfy the primary mission objectives, as in the discussed case of the nanosatellite, the increase in reliability is associated with modest mass and size penalties, as opposed to implementing full redundancy. An extreme case of this design approach is Shinen-2 that, as shown in Fig. 6, consists of two single string systems, one of which is designed to operate a communications subsystem. This reduced the systems complexity to the minimum, while lowering the probability of failure of the telecommunications subsystem as a whole, i.e. failure of both communication lines

(a)

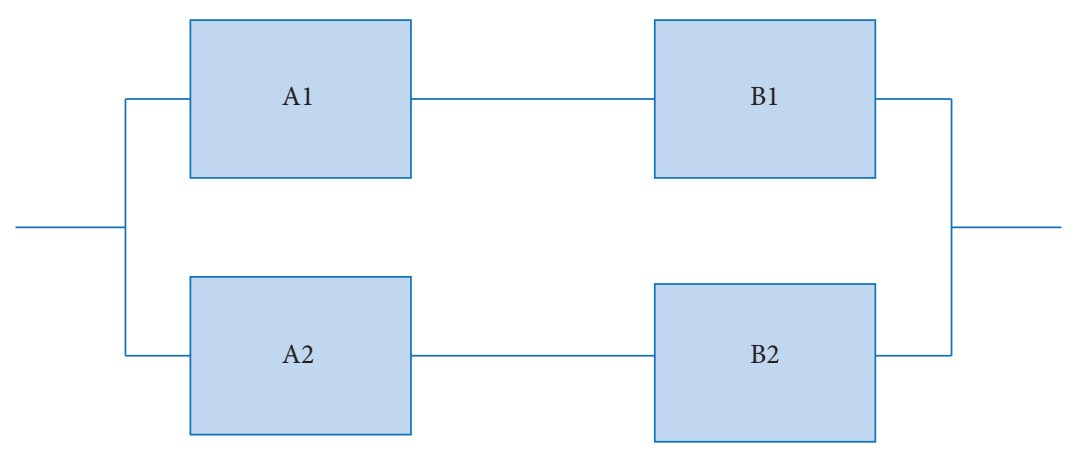

(b)

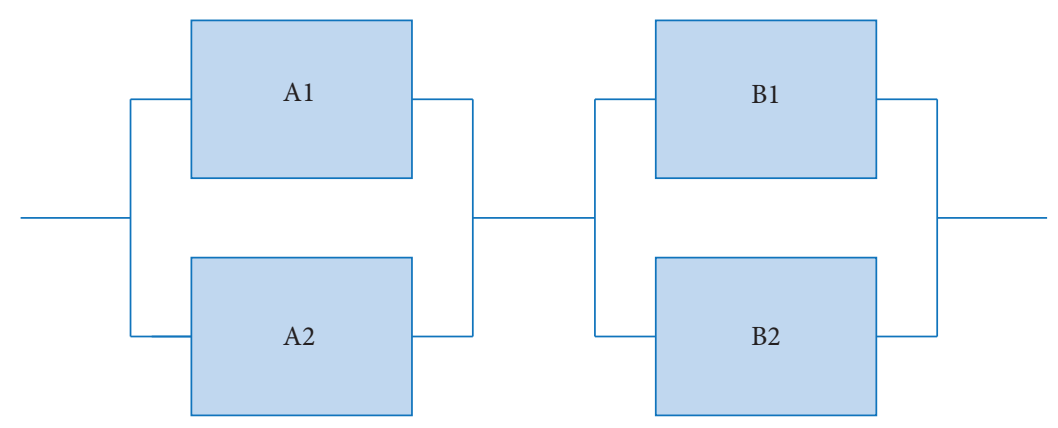

(c)

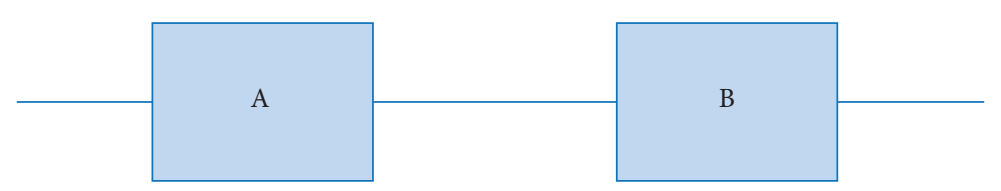

Figure 15. Schematic representations of the two components $A$ and $B$ arranged in architectures with varying levels of redundancy: (a) Dual redundant power system, (b) Fully redundant (cross-strapped) power system and (c) Single string system.

\section{CONCLUSIONS}

The design and implementation of two electrical power systems were presented and illustrated using examples of a nanosatellite and a micro deep-space probe. Both systems had independent solar array inputs and independent battery arrays. Thus the power conditioning unit was split in two separate units in both cases. The efficiency of the COTS DC-DC converters used as power 
conditioning modules was determined by experiment. In addition, telemetry data showed battery voltage and current of solar panels of the micro deep-space probe.

These two examples were cases of single-bus and dual-bus electrical power systems. On the one hand, for the case of the nanosatellite, the two PCMs were rated at different power output to a single-bus, making the secondary system a backup unit that enabled minimum functionality. On the other hand, the electrical power system of the micro deep-space probe was split in two almost identical units (EPS 1 and EPS 2). Each EPS had an independent power bus and, therefore, Shinen-2 operated using a dual-bus electrical power system that had two communication subsystems powered by different power buses.

The advantages of using various configurations of power buses on small satellites were discussed in the context of mass-efficiencydevelopment-random failure trade-off. It was shown, based on the two above satellite examples, that using a dual-power bus can offer increased reliability at a modest increase in mass, volume and complexity, which is also proportional to development risk. Therefore, it is recommended to evaluate the dual-bus power architecture when choosing the EPS architecture for small satellites.

A new satellite mission is being operated by the Kyushu Institute of Technology to continue the evaluation of the redundant electrical power systems in a sun-synchronous orbit. Sensors of solar panel temperatures, sun sensors for attitude determination, and current and voltage measurements at more locations in the EPS will be included to better understand the dual-bus electrical power system behavior.

\title{
AUTHOR'S CONTRIBUTION
}

Conceptualization, Gonzalez-Llorente J; Methodology, Gonzalez-Llorente J and Lidtke AA; Investigation, Gonzalez-Llorente J, Lidtke AA, Hurtado R and Okuyama K; Writing - Original Draft, Gonzalez-Llorente J, Lidtke AA and Hurtado R; Writing Review and Editing, Gonzalez-Llorente J, Lidtke AA and Okuyama K; Funding Acquisition, Okuyama K, Gonzalez-Llorente J and Hurtado R; Resources, Gonzalez-Llorente J and Hurtado R; Supervision, Okuyama K.

\section{FUNDING}

Ministry of Education, Culture, Sports, Science and Technology of Japan [https://doi.org/10.13039/501100001700].

\section{REFERENCES}

\author{
Azur Space (2016) 30\% triple junction gaas solar cell. Azur Space; [accessed 2017 March 3]. http://www.azurspace.com/ \\ images/0003429-01-01_DB_3G30C-Advanced.pdf \\ Babuscia A, Cheung K-M, Divsalar D, Lee C (2015) Development of cooperative communication techniques for a network of small \\ satellites and CubeSats in deep space: the SOLARA/SARA test case. Acta Astronautica 115:349-355. http://doi.org/10.1016/j. \\ actaastro.2015.06.001 \\ Bendoukha SA, Okuyama K, Bianca S, Nishio M (2016) Control system design of an ultra-small deep space probe. Energy Procedia \\ 100:537-550. http://doi.org/10.1016/j.egypro.2016.10.216 \\ Brito MAG, Galotto L, Sampaio LP, Melo GA, Canesin CA (2013) Evaluation of the main MPPT techniques for photovoltaic applications. \\ Industrial Electronics, IEEE Transactions on Industrial Electronics 60(3):1156-1167. http://doi.org/10.1109/TIE.2012.2198036 \\ Carrara V, Januzi RB, Makita DH, Santos LFDP, Sato LS (2017) The ITASAT cubesat development and design. Journal of Aerospace \\ Technology and Management 9(2):138-147. https://doi.org/10.5028/jatm.v9i2.614 \\ Chin KB, Brandon EJ, Bugga RV, Smart MC, Jones SC, Krause FC, West WC, Bolotin GG (2018) Energy storage technologies for small \\ satellite applications. Proceedings of the IEEE 106(3):419-428. https://doi.org/10.1109/JPROC.2018.2793158
}


Crisp NH, Smith K, Hollingsworth P (2015) Launch and deployment of distributed small satellite systems. Acta Astronautica 114:65-78. http://doi.org/10.1016/j.actaastro.2015.04.015

DeGroot MH, Schervish MJ (2014) Probability and Statistics. 4th ed. Harlow: Pearson Education Limited.

Del Corso D, Passerone C, Reyneri L, Sansoe C, Speretta S, Tranchero M (2011) Design of a university nano-satellite: the piCPoT case. IEEE Transactions on Aerospace and Electronic Systems 47(3):1985-2007. https://doi.org/10.1109/TAES.2011.5937278

Edries MY, Tanaka A, HORYU-IV Team, Cho M (2016) Design and testing of electrical power subsystem of a lean satellite, HORYU-IV. Trans JSASS Aerospace Tech Japan 14:7-16. https://doi.org/10.2322/tastj.14.Pf_7

Erb DM, Rawashdeh SA, Lumpp Jr. JE (2011) Evaluation of solar array peak power tracking technologies for CubeSats. Presented at: AIAA/ USU Conference on Small Satellites; Logan, USA.

Frost C, Shimmin R, Agasid E, Burton R, Carlino R, Defouw G, Perez AD, Karacalioglu AG, Klamm B, Rademacher A, et al. (2015) Small spacecraft technology state of the art. (TP-2015-216648). NASA Technical Publication.

Hecht M (2011) Risk and Reliability. In: Wertz, J, Everett DF, Puschell JJ, editors. Space mission engineering: the new SMAD. Hawthorne: Microcosm press.

Kuroiwa F, Okuyama K, Nishio M, Morita H, Szasz B, Bendoukha S, Saganti P, Holland D (2016) A design method of an autonomous control system for a deep-space probe. Trans JSASS Aerospace Tech Japan 14(ists30):105-112. https://doi.org/10.2322/tastj.14.Pf_105

Langer M, Bouwmeester J (2016) Reliability of CubeSats - statistical data, developers' beliefs and the way forward. Presented at: AIAA/ USU Conference on Small Satellites; Logan, USA

Loche D, Labille J-M, Wallecan F, Goeij O (2011) Mono-bus and dual-bus power architecture trade-off for high power LEO Satellite. Presented at: 9th European Space Agency; Saint Raphael, France.

Mishra S (2019) Power supplies for consumer electronic devices. IEEE Potentials 38(1):8-13. https://doi.org/10.1109/ MPOT.2018.2850478

Mourra O, Fernandez A, Tonicello F (2010) Buck Boost Regulator (B2R) for spacecraft Solar Array Power conversion. Presented at: 25th Applied Power Electronics Conference and Exposition; Palm Springs, USA. https://doi.org/10.1109/APEC.2010.5433399

Navarathinam N, Lee R, Chesser $\mathrm{H}$ (2011) Characterization of Lithium-Polymer batteries for CubeSat applications. Acta Astronautica 68(11-12):1752-1760. http://doi.org/10.1016/j.actaastro.2011.02.004

Okada K, Seri Y, Shibagaki R, Masui H, Cho M (2013) On-orbit results of the power system on-board nano-satellite Horyu-II. Presented at: 29th International Symposium on Space Technology and Science; Nagoya, Japan.

Patel M (2005) Spacecraft power system. Boca Raton: CRC Press.

Sanyo Energy (2012) Datasheet of Panasonic Lithium lon NCR18650B. Panasonic; [accessed 2018 February 5]. http://www. batteryspace. com/prod-specs/NCR18650B.pdf

Sarli BV, Ariu K, Yano H (2016) PROCYON's probability analysis of accidental impact on Mars. Advances in Space Research 57(9):20032012. http://doi.org/10.1016/j.asr.2015.11.007

Shirasaka S, Ishibashi K, Nakasuka S (2011) Study on reasonably reliable systems engineering for nano-satellite, The Proceedings of the Space Engineering Conference 19:F4.1-4. https://doi.org/10.1299/jsmesec.2010.19._F4-1_

Swartwout M, Jayne C (2016) University-class spacecraft by the numbers: success, failure, debris. (but mostly success.). Presented at: AIAA/USU Conference on Small Satellites; Logan, USA.

Yoon S, Shin Y, Jeon J, Seo Y, Jeon J, Woo J, Seon J (2014) Analysis of the charged particle radiation effect for a CubeSat transiting from Earth to Mars. Current Applied Physics 14(4):575-581. http://doi.org/10.1016/j.cap.2014.01.018 